\title{
Chest wall volume regulation during exercise in COPD patients with GOLD stages II to IV
}

\author{
I. Vogiatzis*,", G. Stratakos*, D. Athanasopoulos*\#, O. Georgiadou*, S. Golemati*, \\ A. Koutsoukou*, I. Weisman ", C. Roussos* and S. Zakynthinos*
}

ABSTRACT: The present study investigated how end-expiratory ribcage and abdominal volume regulation during exercise is related to the degree of dynamic chest wall hyperinflation in patients with different spirometric severity of chronic obstructive pulmonary disease (COPD) based on the Global Initiative for Chronic Obstructive Lung Disease (GOLD) classification.

In total, 42 COPD patients and 11 age-matched healthy subjects were studied during a rampincremental cycling test to the limit of tolerance (Wpeak). Volume variations of the chest wall (at end expiration (EEVcw) and end inspiration) and its compartments (ribcage (Vrc) and abdominal (Vab)) were computed by optoelectronic plethysmography.

At Weak, only patients in GOLD stages III and IV exhibited a significant increase in EEV cw (increase of $454 \pm 509$ and $562 \pm 363 \mathrm{~mL}$, respectively). These patients did not significantly reduce end-expiratory $\mathrm{Vab}$, whereas patients in GOLD stage II resembled healthy subjects with significantly reduced end-expiratory $V a b$ (decrease of $287 \pm 350 \mathrm{~mL}$ ). In patients, the greater the increase in EEV cw at Wpeak, the smaller the reductions in end-expiratory $V_{a b}$ and the greater the increase in end-expiratory Vrc.

In chronic obstructive pulmonary disease patients with different spirometric disease severity, greater degrees of exercise-induced dynamic chest wall hyperinflation were accompanied by lower degrees of end-expiratory abdominal volume displacement and larger increases in endexpiratory ribcage volume.

KEYWORDS: Chronic obstructive pulmonary disease, dynamic hyperinflation, exercise, Global Initiative for Chronic Obstructive Lung Disease stages

E xercise-induced dynamic hyperinflation refers to the temporary increase in endexpiratory lung volume above the baseline value that takes place not only in patients with moderate and severe chronic obstructive pulmonary disease (COPD) [1, 2] but also in patients with mild COPD [3], thereby limiting their exercise tolerance. Therapeutic interventions, such as bronchodilators [4, 5], oxygen supplementation [6,7] and rehabilitative exercise training [8, 9] improve exercise tolerance by reducing the degree of dynamic hyperinflation. Measurement of operational lung volumes is therefore crucial in order to evaluate the effectiveness of these therapeutic interventions. To this end, optoelectronic plethysmography (OEP) has become a very useful method because it assesses breath-by-breath volume variations of the total chest wall and its compartments during exercise, i.e. ribcage and abdominal $[1,4,9,10]$.
Two recent studies by ALIVERTI et al. [4] and GEORGIADOU et al. [9] investigated the effects of bronchodilators and exercise training, respectively, on the chest wall volume regulation during exercise, using the OEP method. They concluded that the changes seen in exerciseinduced chest wall hyperinflation after these interventions were almost exclusively attributable to changes of the abdominal and not the ribcage compartmental volumes. Interestingly, in the study by GEORGIADOU et al. [9], the traininginduced reduction in end-expiratory abdominal volume was significantly correlated with the improvement in exercise tolerance.

In addition, it has been documented that patients who progressively hyperinflate during exercise are not effective in reducing their end-expiratory abdominal volume, whereas those who delay or even avoid increasing end-expiratory chest wall

\section{AFFILIATIONS}

*Dept of Critical Care Medicine and Pulmonary Services, Evangelismos Hospital, Pulmonary Rehabilitation Centre, "M. Simou and G.P. Livanos" Laboratories, and

\#Dept of Physical Education and Sport Science, National \& Kapodistrian University of Athens, Athens, Greece.

-World Wide Medical, Pfizer Inc. New York, NY, USA.

\section{CORRESPONDENCE}

I. Vogiatzis

Thorax Foundation

3 Ploutarhou Str. 10675

Athens

Greece

Fax: 302107239127

E-mail: gianvog@phed.uoa.gr

Received:

November 192007

Accepted after revision:

February 142008

SUPPORT STATEMENT

The present study was supported, in part, by the European Community CARED FP5 project (contract number: QLG5-CT-2002-0893) and the Thorax Foundation.

STATEMENT OF INTEREST

A statement of interest for I. Weisman and for the study itself can be found at www.erj.ersjournals.com/misc/ statements.shtml 
volume $\left(\mathrm{EEV}_{\mathrm{cw}}\right)$ with increasing exercise intensity exhibit significant reductions in end-expiratory abdominal volume $[1,10]$. Furthermore, in a recent study documenting reductions in exercise-induced chest wall hyperinflation after bronchodilator therapy, the essential difference between those patients who improved their exercise tolerance (improvers) and those who did not (nonimprovers) was in the degree of endexpiratory abdominal volume change; it was suggested that there was a different degree of expiratory muscle recruitment between improvers and nonimprovers [4]. Earlier reports on different patterns of expiratory muscle recruitment in patients with COPD were controversial [11, 12]. POTTER et al. [11] suggested that in some patients, excessive recruitment of expiratory muscles during exercise may lead to dynamic airway compression, thus limiting expiratory flow, whereas LEAVER and PRIDE [12] maintained that expiratory transthoracic pressures meet but do not exceed the critical closure pressure during exercise in COPD.

Based on the previous studies, it is apparent that the pattern of end-expiratory dynamic chest wall hyperinflation and its modulation during exercise depends on the regulation of end-expiratory abdominal volume [1, 4, 9, 10]. As previous studies $[9,10]$ have suggested, the likelihood of exhibiting dynamic chest wall hyperinflation during exercise increases with increasing lung disease severity, manifested by the greater degrees of resting airway obstruction $[9,10]$ and expiratory flow limitation $[2,3]$. The present authors therefore reasoned that in COPD patients with different lung disease severity, greater degrees of exercise-induced dynamic chest wall hyperinflation would be accompanied by lesser reductions in end-expiratory abdominal volume. The purpose of the present study was therefore to determine how end-expiratory abdominal volume regulation during exercise is related to the degree of dynamic chest wall hyperinflation in patients with different spirometric severity of COPD based on Global Initiative for Chronic Obstructive Lung Disease (GOLD) classification.

\section{METHODS}

\section{Subjects}

In total, 42 patients (15 female) with clinically stable COPD participated in the study according to the following inclusion criteria: 1) a post-bronchodilator forced expiratory volume in one second (FEV1) $<80 \%$ predicted without significant reversibility $(<12 \%$ change of the initial FEV1 value or $<200 \mathrm{~mL}$ ); 2) optimal medical therapy according to GOLD [13]; and 3) the absence of other significant diseases that could contribute to exercise limitation. Of these patients, 22 had also participated in previous studies at the present authors' laboratory $[1,9]$. A total of 11 age-matched healthy subjects (three female) with FEV1 $>92 \%$ pred were also studied. Patients gave informed consent that was approved by the University Ethics Committee (National and Kapodistrian University of Athens, Athens, Greece).

\section{Study design}

COPD patients were classified into GOLD stages II, III and IV using post-bronchodilator spirometric criteria. The classification of severity was as follows: moderate COPD (stage II), 50\% $\leqslant$ FEV1 <80\%; severe COPD (stage III), 30\% $\leqslant$ FEV1 <50\%; and very severe COPD (stage IV), FEV1 $<30 \%$. Patients who had previously participated in studies at the present authors' laboratory repeated the present study and were almost evenly distributed across the three GOLD stages (i.e. seven patients in GOLD stage II, seven patients in stage III and eight patients in stage IV). Healthy subjects were consecutively recruited from the local community on the basis of their age (i.e. $<55 \mathrm{yrs}$ ). Patients and healthy subjects were assessed for pulmonary function and underwent an incremental cycle exercise test to the limit of tolerance.

\section{Pulmonary function assessment}

Spirometry and measurement of diffusing factor of the lung for carbon monoxide (DL,CO; Masterlab; Jaeger, Wurzburg, Germany) and lung volumes by body plethysmography (Medgraphics Autolink 1085D; Medical Graphics, St Paul, MN, USA) were performed according to recommended standards [14].

\section{Exercise testing protocols}

All subjects performed an incremental test with a ramp increase of load (increments of 5 or $10 \mathrm{~W} \cdot \mathrm{min}^{-1}$ and 15 or $20 \mathrm{~W} \cdot \mathrm{min}^{-1}$ for COPD patients and healthy subjects, respectively) to the limit of tolerance (Wpeak) on an electromagnetically braked cycle ergometer (Ergoline 800; Sensor Medics, Anaheim, CA, USA). The test consisted of $3 \mathrm{~min}$ of measurements at rest $(R)$, followed by 3 min of unloaded pedalling. Throughout the exercise, test subjects were encouraged to maintain a pedalling frequency of 60 revolutions $\cdot \mathrm{min}^{-1}$.

During the test, flow rate at the mouth and gas exchange variables were recorded breath-by-breath (Vmax 229; Sensor Medics). Cardiac frequency $(f C)$ and percentage oxygen saturation were determined using the R-R interval from a 12lead online electrocardiogram (Marquette Max; Marquette Hellige $\mathrm{GmbH}$, Freiburg, Germany) and a pulse oximeter (Nonin 8600; Nonin Medical, North Plymouth, MN, USA), respectively. Subjects wore a nose-clip and breathed through a low dead space mouthpiece. Flow was measured with a hotwire pneumotachograph (Vmax 229; Sensor Medics; $70 \mathrm{~mL}$ dead space) near the mouthpiece and lung volume changes were obtained by integrating the flow signal. A gas mixture (inspiratory oxygen fraction of 0.26 balanced with nitrogen) was inspired by all patients from a Douglas bag through a twoway non-rebreathing valve (Model 2700; Hans Rudolph, Kansas City, MO, USA; $115 \mathrm{~mL}$ dead space) connected to the pneumotachograph. The flow into the Douglas bag was constant and patients breathed the gas mixture at the rate that they demanded. Avoiding desaturation during exercise, in order to exclude hypoxia and its variable effects on different patients, was a key point of the present protocol. In addition, oxygen supplementation was important in patients with GOLD stages III and IV in order to prevent severe arterial hypoxaemia and hence premature cessation of exercise. Accordingly, it was decided to supply oxygen to all patients studied. Healthy subjects breathed room air through the mouthpiece and pneumotachograph. Symptom ratings were monitored every $2 \mathrm{~min}$ throughout exercise using the 1-10 Borg scale [15]. The V-slope technique was used to detect the oxygen uptake $\left(V^{\prime} \mathrm{O}_{2}\right)$ at which the anaerobic threshold occurred [16]. The change in $V^{\prime} \mathrm{O}_{2}$ as a function of work rate 
(WR) was calculated $\left(\Delta V^{\prime} \mathrm{O}_{2} / \Delta \mathrm{WR}\right)$ as an index of aerobic work efficiency [17]. In addition, the oxygen pulse was calculated by dividing the $V^{\prime} \mathrm{O}_{2}$ by $f C$ [17].

\section{Chest wall volume and respiratory pressure measurements}

Volumes of the total chest wall $\left(V_{\mathrm{cw}}\right)$ and its compartments, the ribcage and the abdomen were measured by OEP (BTS, Milan, Italy) as previously described $[1,4,9,10]$. Throughout the test, subjects were asked to maintain an upright posture while seated on the bicycle ergometer with a modified handle bar (similar to the one used by professional cyclists), so that the arms were kept away from the trunk while the hands were grasping the handle in order to make all markers visible. In order to obtain $V_{\mathrm{cw}}$ at total lung capacity (TLC $\mathrm{cw}$ ) during rest and exercise, subjects were asked to perform inspiratory capacity (IC) manoeuvres as previously described [1, 9]. Flow limitation at rest and during exercise was determined by inspection of the tidal flow-volume loop in relation to the expiratory boundary of the maximal flow-volume curve, as previously described [18]. The inspiratory reserve chest wall volume (IRV cw) was calculated as the difference between the end-inspiratory $V_{\mathrm{cw}}$ and the TLC $\mathrm{cw}$. IC was also measured by the OEP (ICOEP) as the difference between TLC $c w$ and EEV $\mathrm{Cw}_{\mathrm{c}}$; the latter value was derived by averaging the EEVcw over a period of $20 \mathrm{~s}$ prior to the IC effort $[1,9,19]$. ICOEP values recorded during rest and exercise were compared with the corresponding IC values measured by the spirometer (ICSP). From the breath-by-breath $V_{\mathrm{cw}}$ measurements, ventilatory and breathing pattern parameters were determined by calculating the average values during data acquisition, performed by OEP, which was interrupted for $30 \mathrm{~s}$ every $2 \mathrm{~min}$ in order to allow safe data storage. Comparison of compartmental $V_{\mathrm{cw}}$ and breathing pattern parameters at given ventilation were made over each of the data acquisition periods.

In 12 subjects (three patients from each GOLD stage and three healthy subjects), swings in oesophageal pressure (Poes), and gastric pressure $(P$ ga $)$ were continuously monitored during exercise. Poes and Pga were assessed by two commercially available thin-walled balloon catheters (Ackrad Laboratories Inc., Crandford, NJ, USA) coupled with differential pressure transducers (MP-45, $\pm 250 \mathrm{cmH}_{2} \mathrm{O}$; Validyne Corp., Northridge, CA, USA). Pressures and flow signals were synchronised to those of the motion analyser and recorded by the same computer used for OEP.

\section{Statistical analysis}

Data are presented as mean \pm SD. Group comparisons at baseline characteristics were performed using one-way ANOVA. Two-way ANOVA with repeated measures was used to identify statistically significant differences in total and compartmental $V_{\mathrm{cw}}$ across different time-points during exercise between the four groups. ANOVA was followed by a least significant difference test for post hoc analyses when necessary. For each GOLD stage and for the healthy group, independent unpaired t-tests were applied to assess differences between IC values assessed at the limit of tolerance by the spirometer and by OEP. Linear regression analyses were performed using the least square method. Qualitative variables were compared by Fisher's exact test. Stepwise multiple regression analysis established the best predictive equations for W peak (dependent variable). Independent variables included resting lung function measurements, and peak exercise gas exchange and breathing pattern measurements and chest wall volume variations. A p-value $<0.05$ was considered to be statistically significant.

\section{RESULTS}

\section{Baseline characteristics}

Lung function data for the patients and the healthy subjects are shown in table 1. Compared with GOLD stage II, COPD patients in GOLD stages III and IV had significantly lower FEV1, forced vital capacity (FVC), FEV1/FVC (\%), mean forced expiratory flow between 25 and $75 \%$ of FVC, DL,CO \% pred and IC, and significantly higher residual volume. Patients in GOLD stage IV also had higher functional residual capacity compared with those in GOLD stage II. Patients in GOLD stage IV had lower FEV1, FEV1/FVC (\%) and DL,CO \% pred compared with those in GOLD stage III. Expiratory flow limitation at rest was

\begin{tabular}{|c|c|c|c|c|}
\hline \multirow[t]{3}{*}{ TABLE 1} & \multicolumn{4}{|c|}{$\begin{array}{l}\text { Demographic and lung function characteristics } \\
\text { of chronic obstructive pulmonary disease } \\
\text { oatients and age-matched healthy subjects }\end{array}$} \\
\hline & \multirow[t]{2}{*}{ Healthy } & \multicolumn{3}{|c|}{ GOLD } \\
\hline & & Stage II & Stage III & Stage IV \\
\hline Subjects $n$ & 11 & 14 & 14 & 14 \\
\hline Age yrs & $61 \pm 11$ & $67 \pm 7$ & $64 \pm 8$ & $58 \pm 7$ \\
\hline Sex M/F n & $8 / 3$ & $8 / 6$ & $9 / 5$ & $10 / 4$ \\
\hline Height $\mathrm{cm}$ & $161 \pm 8$ & $168 \pm 8$ & $165 \pm 6$ & $169 \pm 9$ \\
\hline Weight kg & $70 \pm 13$ & $77 \pm 34$ & $67 \pm 8$ & $68 \pm 10$ \\
\hline BMI $\mathrm{kg} \cdot \mathrm{m}^{-2}$ & $26.6 \pm 3.53$ & $26.0 \pm 4.16$ & $24.8 \pm 3.15$ & $23.8 \pm 2.46$ \\
\hline FEV $_{1} \mathrm{~L}$ & $3.12 \pm 0.92$ & $1.61 \pm 0.35^{\#}$ & $1.11 \pm 0.23^{\# \cdot \bullet}$ & $0.71 \pm 0.14^{\#, \cdot,+}$ \\
\hline $\mathrm{FEV}_{1} \%$ pred & $98 \pm 13$ & $61 \pm 8^{\#}$ & $42 \pm 4^{\# \cdot 9}$ & $24 \pm 3^{\# \cdot \cdot++}$ \\
\hline FVC L & $4.26 \pm 0.82$ & $3.17 \pm 0.69^{\#}$ & $2.63 \pm 0.72^{\# \cdot 9}$ & $2.61 \pm 0.74^{\#, 9}$ \\
\hline FVC \% pred & $106 \pm 17$ & $93 \pm 14$ & $80 \pm 17^{\# \cdot 9}$ & $69 \pm 14^{\# \cdot 9}$ \\
\hline 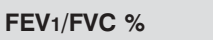 & $75 \pm 10$ & $51 \pm 6^{\#}$ & $44 \pm 10^{\# \cdot \cdot}$ & $28 \pm 5^{\#, \cdot,+}$ \\
\hline FEF $25-75 \% \mathrm{~L} \cdot \mathrm{s}^{-1}$ & $2.73 \pm 1.52$ & $0.62 \pm 0.27^{\#}$ & $0.36 \pm 0.13^{\# \cdot \bullet}$ & $0.24 \pm 0.07^{\#, 9}$ \\
\hline FEF $25-75 \% \%$ pred & $93 \pm 51$ & $26 \pm 12^{\#}$ & $13 \pm 5^{\# \cdot \bullet}$ & $8 \pm 4^{\#, 9}$ \\
\hline DL,Co \% pred & $81 \pm 38$ & $61 \pm 23^{\#}$ & $46 \pm 14^{\#, 9}$ & $32 \pm 12^{\# \cdot,++}$ \\
\hline TLC L & $6.16 \pm 0.97$ & $7.46 \pm 1.15$ & $6.98 \pm 0.86$ & $8.35 \pm 1.82^{\#}$ \\
\hline TLC \% pred & $97 \pm 11$ & $119 \pm 12$ & $117 \pm 12$ & $133 \pm 22^{\#}$ \\
\hline FRC L & $3.22 \pm 0.92$ & $5.11 \pm 0.73^{\#}$ & $5.19 \pm 0.67^{\#}$ & $6.28 \pm 1.14^{\# \cdot \cdot}$ \\
\hline FRC $\%$ pred & $96 \pm 12$ & $153 \pm 19^{\#}$ & $162 \pm 14^{\#}$ & $196 \pm 36^{\#, \bullet}$ \\
\hline RV L & $1.93 \pm 0.77$ & $3.88 \pm 0.62^{\#}$ & $4.27 \pm 0.70^{\#, \cdot}$ & $4.92 \pm 0.98^{\#, \cdot}$ \\
\hline RV \% pred & $88 \pm 31$ & $169 \pm 27^{\#}$ & $186 \pm 28^{\# \cdot 9}$ & $244 \pm 46^{\#, 9}$ \\
\hline IC L & $2.86 \pm 0.91$ & $2.15 \pm 0.61^{\#}$ & $2.02 \pm 0.38^{\# \cdot 9}$ & $2.00 \pm 0.89^{\#, 9}$ \\
\hline IC \% pred & $92 \pm 24$ & $80 \pm 16^{\#}$ & $65 \pm 12^{\#, 9}$ & $66 \pm 20^{\#, \cdot}$ \\
\hline
\end{tabular}

Data are presented as mean \pm SD, unless otherwise stated. GOLD: Global Initiative for Chronic Obstructive Lung Disease; M: male; F: female; BMI: body mass index; FEV1: forced expiratory volume in one second; \% pred: \% predicted; FVC: forced vital capacity; FEF25-75\%: mean forced expiratory flow between 25 and $75 \%$ of FVC; DL,CO: diffusing factor of the lung for carbon monoxide; TLC: total lung capacity; FRC: functional residual capacity; RV: residual volume; IC: inspiratory capacity. ${ }^{*}: p<0.05$ compared with healthy subjects; ": $p<0.05$ compared with GOLD stage II patients; ${ }^{+}$: $p<0.05$ compared with GOLD stage III patients. 
observed in five patients with GOLD stage II, 10 patients with GOLD stage III and all patients with GOLD stage IV.

\section{Peak physiological responses}

Compared with healthy subjects, COPD patients with GOLD stages II-IV exhibited an impaired exercise capacity (table 2) as indicated by the lower $W_{\text {peak }}(\mathrm{p}=0.0001)$, peak $V^{\prime} \mathrm{O}_{2}(\mathrm{p}=0.0001)$ and anaerobic threshold $(\mathrm{p}=0.004)$. Compared with GOLD stage III and II, patients with stage IV were characterised by greater impairment in Wpeak $(\mathrm{p}=0.001), V^{\prime} \mathrm{O}_{2} \quad(\mathrm{p}=0.001)$, oxygen pulse $(p=0.004)$ and anaerobic threshold $(p=0.02)$, which was discernible in all patients with GOLD stage II, 10 out of 14 patients with GOLD stage III and eight out of 14 patients with GOLD stage IV COPD (table 2). At the limit of tolerance, dyspnoea sensation in patients with GOLD stages III and IV was significantly greater compared with healthy subjects and stage II patients (table 2). Healthy subjects experienced greater leg discomfort $(p=0.011)$ compared with COPD patients with GOLD stages III and IV. The majority of patients with stages III and IV ceased exercise due to dyspnoea, whereas the majority of GOLD stage II patients and healthy subjects terminated exercise due to leg discomfort $(p=0.03-0.001$; table 2).

In comparison with healthy subjects, COPD patients of all stages demonstrated at peak exercise lower $(\mathrm{p}=0.001)$ minute ventilation $\left(V^{\prime} \mathrm{E}\right)$, which was due to lower tidal volume $(V \mathrm{~T}$; $\mathrm{p}=0.001)$, as respiratory frequency did not differ $(\mathrm{p}=0.677)$ among groups (table 3 ). Expiratory flow rate ( $V \mathrm{~T} /$ expiratory time $(t E))$ was lower in COPD patients compared with healthy subjects; $V \mathrm{~T} / \mathrm{tE}$ was lower $(\mathrm{p}=0.0001)$ only in GOLD stage IV patients relative to GOLD stage II. $V$ T and inspiratory time $(t \mathrm{I})$ were significantly lower in GOLD stages III and IV relative to GOLD stage II. At the limit of tolerance, expiratory flow limitation was present in four out of 11 healthy subjects, in six patients with GOLD stage II, in 12 patients with GOLD stage III and in all patients with GOLD stage IV.

\section{Operational volumes and respiratory pressures during exercise}

During incremental exercise, a different pattern in operational chest wall volume regulation was observed between healthy and COPD groups (fig. 1). The difference in the pattern was mainly due to a significant difference $(p=0.0001)$ in the endexpiratory and -inspiratory reserve volumes from rest across the exercise time-points. Accordingly, at the limit of tolerance in healthy subjects, mean end-expiratory volume was decreased $(p=0.002)$ by $339 \pm 619 \mathrm{~mL}$ (table 3; fig. $1 \mathrm{a})$. At the end of exercise, the mean end-expiratory chest wall volume remained unchanged (table 3; fig. 1b) in patients with GOLD stage II. However, the response was variable among these patients, since four of them had increased end-expiratory volume by $>200 \mathrm{~mL}$ and three by $\sim 100 \mathrm{~mL}$, whereas in the remaining seven, end-expiratory volume was either unchanged from rest or had decreased by as much as $450 \mathrm{~mL}$. The majority of patients (22 out of 28) in GOLD stages III $(n=10)$ and IV $(n=12)$ exhibited a progressive increase in endexpiratory chest wall volume by $>200 \mathrm{~mL}$ during exercise. At the limit of tolerance, GOLD stage III and IV patients had a significant increase $(\mathrm{p}=0.003)$ in end-expiratory volume (by $454 \pm 509$ and $562 \pm 363 \mathrm{~mL}$, respectively) the magnitude of which differed significantly $(p=0.001)$ from that in GOLD

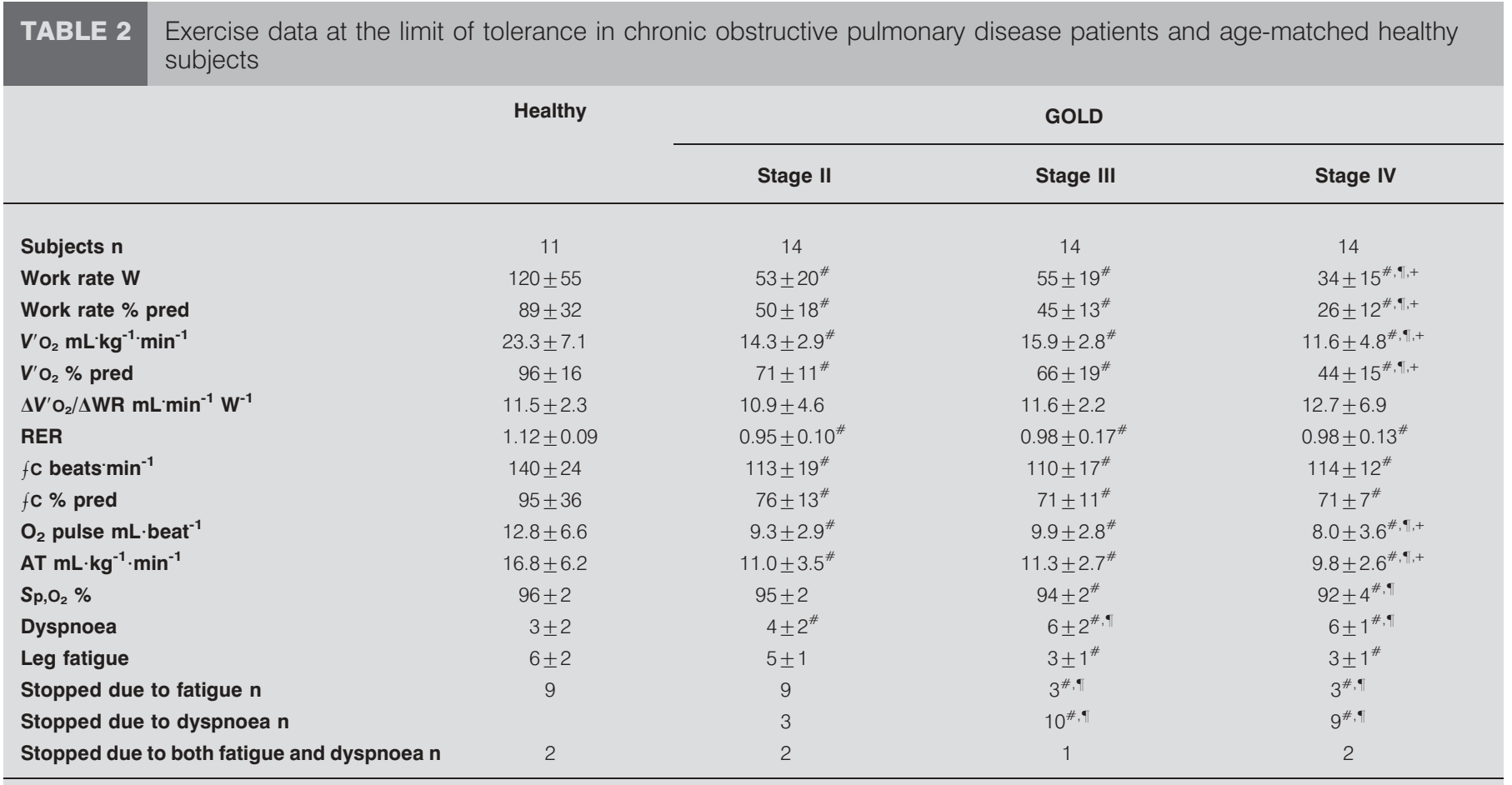

Data are presented as mean $\pm \mathrm{SD}$, unless otherwise stated. GOLD: Global Initiative for Chronic Obstructive Lung Disease; \% pred: \% predicted; $V^{\prime} \mathrm{O}_{2}$ : oxygen uptake $\Delta V^{\prime} \mathrm{O}_{2} / \Delta$ WR: aerobic work efficiency; RER: respiratory exchange ratio; $f \mathrm{C}$ : cardiac frequency; $\mathrm{O}_{2}$ pulse: oxygen pulse; AT: anaerobic threshold; $\mathrm{Sp}, \mathrm{O}_{2}:$ oxygen saturation \#: $p<0.05$ compared with healthy subjects; ${ }^{\prime \prime}: p<0.05$ compared with GOLD stage II patients; ${ }^{+}: p<0.05$ compared with GOLD stage III patients. 


\begin{tabular}{|c|c|c|c|c|}
\hline \multirow[t]{3}{*}{ TABLE 3} & \multicolumn{4}{|c|}{$\begin{array}{l}\text { Ventilatory responses at the limit of tolerance in } \\
\text { chronic obstructive pulmonary disease patients } \\
\text { and age-matched healthy subjects }\end{array}$} \\
\hline & \multirow[t]{2}{*}{ Healthy } & \multicolumn{3}{|c|}{ GOLD } \\
\hline & & Stage II & Stage III & Stage IV \\
\hline Subjects $n$ & 11 & 14 & 14 & 14 \\
\hline$V^{\prime} E \mathrm{~L} \cdot \mathrm{min}^{-1}$ & $68.7 \pm 13.8$ & $38.4 \pm 8.9^{\#}$ & $36.5 \pm 8.4^{\#}$ & $27.6 \pm 7.2^{\# \cdot 9_{i}+}$ \\
\hline$V T \mathbf{L}$ & $2.37 \pm 0.57$ & $1.33 \pm 0.34^{\#}$ & $1.21 \pm 0.27^{\# \cdot 9}$ & $1.10 \pm 0.32^{\#, 9,+}$ \\
\hline$f R$ breaths $\min ^{-1}$ & $29 \pm 4$ & $30 \pm 6$ & $30 \pm 6$ & $26 \pm 10^{\# \cdot 9_{+}+}$ \\
\hline$t \mid \mathrm{s}$ & $0.95 \pm 0.12$ & $0.97 \pm 0.27$ & $0.71 \pm 0.14^{\# \cdot 9}$ & $0.81 \pm 0.21^{\#, 9,+}$ \\
\hline$t E S$ & $1.21 \pm 0.18$ & $1.26 \pm 0.30$ & $1.15 \pm 0.24$ & $1.61 \pm 0.39^{\#, 9,+}$ \\
\hline$t / /$ tot & $0.44 \pm 3.44$ & $0.41 \pm 0.45$ & $0.38 \pm 0.52^{\#}$ & $0.33 \pm 0.48^{\#}$ \\
\hline$V T / t E L \cdot s^{-1}$ & $2.03 \pm 0.58$ & $1.19 \pm 0.40^{\#}$ & $1.07 \pm 0.31^{\#}$ & $0.89 \pm 0.34^{\#, 9}$ \\
\hline ICSP L & $2.87 \pm 0.76$ & $1.87 \pm 0.48^{\#, 5}$ & $1.48 \pm 0.34^{\# \cdot \bullet}$ & $1.37 \pm 0.34^{\# \cdot}$ \\
\hline$\triangle I C s P$ L & $0.01 \pm 0.10$ & $-0.28 \pm 0.12^{\#}$ & $-0.54 \pm 0.24^{\#, 9}$ & $-0.63 \pm 0.35^{\#, \bullet}$ \\
\hline ICOEP L & $2.85 \pm 0.89$ & $2.02 \pm 0.63^{\#}$ & $1.48 \pm 0.37^{\# \cdot}$ & $1.39 \pm 0.37^{\#, 9}$ \\
\hline$\Delta \mathrm{EIV}$ cw mL & $2036 \pm 658$ & $1608 \pm 527^{\#}$ & $1740 \pm 591^{\#}$ & $1764 \pm 609^{\#}$ \\
\hline$\Delta \mathrm{EEV}$ cw $\mathrm{mL}$ & $-339 \pm 619$ & $85 \pm 288^{\#}$ & $454 \pm 509^{\# \cdot 9}$ & $562 \pm 363^{\#, 9}$ \\
\hline IRV cw mL & $573 \pm 374$ & $530 \pm 467$ & $221 \pm 273^{\#, 9}$ & $167 \pm 322^{\#, 9}$ \\
\hline
\end{tabular}

Data are presented as mean $\pm \mathrm{SD}$, unless otherwise stated. GOLD: Global Initiative for Chronic Obstructive Lung Disease; $V^{\prime} E$ : minute ventilation; VT: tidal volume; fR: breathing frequency; $t \mathrm{t}$ : inspiratory time; $t E$ : expiratory time; tI/ttot: duty cycle; VT/tE: expiratory flow rate; ICSP: inspiratory capacity (IC) calculated by spirometry; $\triangle$ ICSP: change from rest in spirometric IC; ICOEP: IC assessed by optoelectronic plethysmography; $\Delta$ EIV $\mathrm{cw}$ : end-inspiratory chest wall volume as a difference from rest; $\Delta E E V_{c w}$ : end-expiratory chest wall volume as a difference from rest; IRVcw: inspiratory reserve chest wall volume. ${ }^{*}: p<0.05$ compared with healthy subjects; ": $p<0.05$ compared with GOLD stage II patients; +: $p<0.05$ compared with GOLD stage III patients; ${ }^{\text {s. }} p<0.05$ compared with ICOEP.

stage II (table 3; fig. 1b-d). The difference in end-expiratory volume between patients in GOLD stages III and IV compared with those in GOLD stage II was also reflected in the IC measured by spirometry and OEP (table 3).

Volume constraints on $V \mathrm{~T}$ expansion at the limit of tolerance were significantly increased as disease severity, classified by spirometry, progressed compared with healthy subjects (table 3; fig. 1). Indeed, IRVCw in GOLD stages III and IV patients $(221 \pm 273$ and $167 \pm 322 \mathrm{~mL}$, respectively) was significantly lower $(p=0.021)$ compared with GOLD stage II patients $(530 \pm 467 \mathrm{~mL})$ and healthy subjects $(573 \pm 374 \mathrm{~mL}$; table 3; fig. 1).

The differences in $\mathrm{EEV}_{\mathrm{cw}}$ between the groups were mainly attributable to changes in the end-expiratory abdominal volume, which was different $(p=0.003)$ among the four groups across the exercise levels (fig. $2 \mathrm{~b}, \mathrm{~d}, \mathrm{f}$ and $\mathrm{h}$ ). Post hoc analysis showed that GOLD stage III and IV patients (fig. $2 \mathrm{f}$ and $\mathrm{h}$ ) differed $(p=0.002)$ from GOLD stage II and healthy subjects (fig. $2 b$ and $d$ ); the end-expiratory abdominal volume at the limit of tolerance in the former groups (GOLD stages III and IV) did not change from rest, whereas in the latter groups (GOLD stage II and healthy subjects) the end-expiratory abdominal volume was reduced $(\mathrm{p}<0.05)$ from rest by
$287 \pm 350$ and $602 \pm 724 \mathrm{~mL}$, respectively. This reduction in end-expiratory abdominal volume in healthy subjects was greater $(p=0.03)$ compared with that in stage II patients. Considering data from COPD patients in all three stages, the changes from rest to the limit of tolerance in end-expiratory abdominal volume were correlated with the changes in EEV cw $(r=0.76, p=0.0001$; SEE: 0.243). When considering data from all patients and healthy controls, changes from rest to the limit of tolerance in end-expiratory abdominal volume were also correlated with the changes in $\operatorname{EEV}_{\mathrm{cw}}(\mathrm{r}=0.84, \mathrm{p}=0.0001$; SEE: 0.277).

Interestingly, only COPD patients exhibited a progressive increase $(p=0.0001)$ in end-expiratory ribcage volume (fig. $2 b$, $\mathrm{d}, \mathrm{f}$ and $\mathrm{h}$ ) during exercise. Further statistical analysis revealed a significant interaction $(p=0.0001)$ between patient GOLD stage and exercise level, showing that the rate of increase in end-expiratory ribcage volume from rest differed between groups. In fact, during exercise, the end-expiratory ribcage volume reached $578 \pm 365$ and $523 \pm 311 \mathrm{~mL}$ for GOLD stages IV and III (fig. 2e and g), respectively. Both were higher $(\mathrm{p}=0.045)$ than those for GOLD stage II and healthy subjects ( $355 \pm 323$ and $263 \pm 271 \mathrm{~mL}$, respectively; fig. $2 \mathrm{a}$ and c). Endexpiratory ribcage volume at the limit of tolerance in stage II patients was not significantly higher than in healthy controls. In COPD patients of all stages, the changes from rest to the limit of tolerance in end-expiratory ribcage volume were correlated with the changes in EEV $\mathrm{cw}(\mathrm{r}=0.62, \mathrm{p}=0.001$; SEE: $0.330)$; in COPD patients combined with healthy controls, this correlation also existed $(r=0.44, p=0.002$; SEE: 0.483).

The end-inspiratory ribcage volume (fig. 2a, c, e and g) was also increased $(\mathrm{p}=0.0001)$ from rest to peak exercise and was not different $(p=0.880)$ among all groups $(1,093 \pm 399$, $838 \pm 331,1,017 \pm 406$ and $924 \pm 498 \mathrm{~mL}$ for healthy subjects, GOLD stages II, III and IV, respectively). Similarly, the endinspiratory abdominal volume (fig. $2 \mathrm{~b}, \mathrm{~d}, \mathrm{f}$ and $\mathrm{h}$ ) rose $(p=0.001)$ from rest to peak exercise and there was a significant difference $(\mathrm{p}<0.05)$ among patient groups and healthy controls $(944 \pm 534,753 \pm 381,814 \pm 327$ and $804 \pm 394 \mathrm{~mL}$ for healthy subjects, GOLD stages II, III and IV, respectively).

Figure 3 shows changes in end-expiratory and end-inspiratory total and compartmental chest wall volumes plotted as function of $V^{\prime} E$. For a given level of ventilation during the incremental exercise test, $\mathrm{EEV}_{\mathrm{cw}}$ was greater in GOLD stages III and IV than in stage II, and it was also greater in GOLD stage IV than in stage III (fig. 3a). End-expiratory ribcage volume in stage IV was greater than in stages II and III (fig. 3c). Furthermore, for given ventilation, end-expiratory abdominal volume in GOLD stage II was significantly lower than in stage III (fig. 3e).

Figure 4 shows changes in breathing pattern variables plotted as a function of $V^{\prime} E$ during exercise in patients with GOLD stages II and III. At a given ventilation, stage II patients exhibited a significantly higher duty cycle ( $t \mathrm{I} /$ total time of respiratory cycle $t$ tot) and mean expiratory flow rate $(V \mathrm{~T} / t \mathrm{E})$.

Figure 5 shows end-expiratory Pga during exercise in a limited number of patients $(\mathrm{n}=9)$. During exercise, end-expiratory $P$ ga was greater, albeit not significantly, in patients with GOLD stage II compared with patients with GOLD stages III and IV. 

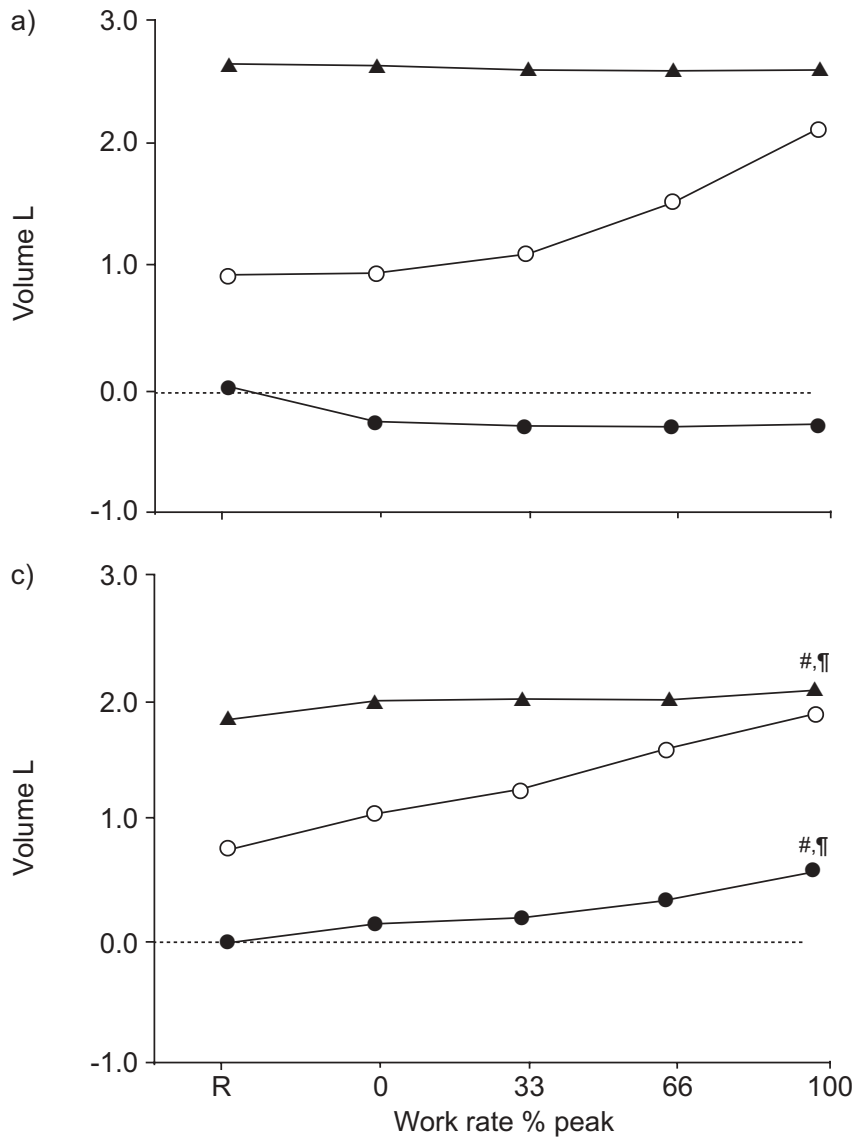

b)

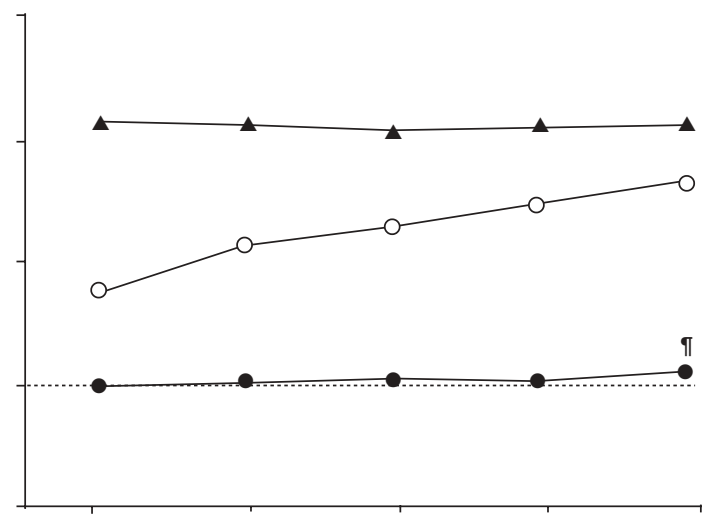

d)

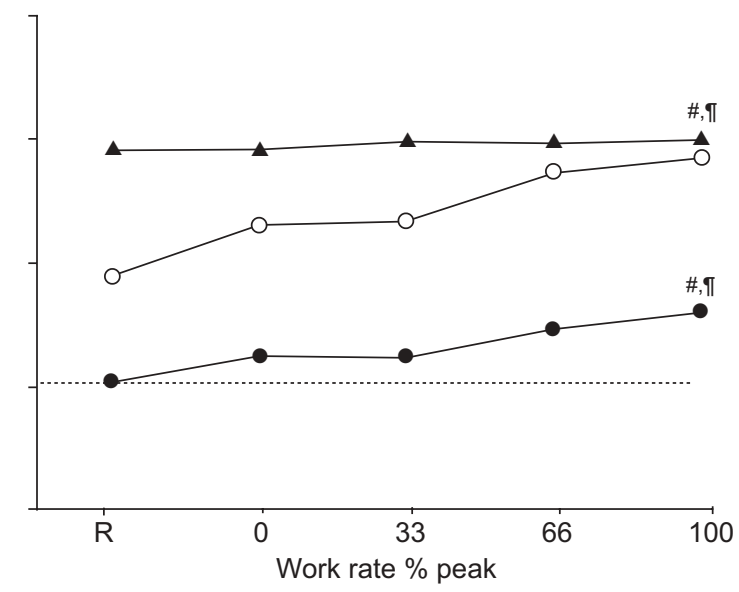

FIGURE 1. Volumes of the total chest wall in a) healthy subjects and patients with b) Global Initiative for Chronic Obstructive Lung Disease (GOLD) stage II, c) stage III and d) stage IV during incremental exercise. End-inspiratory $(O)$ and end-expiratory $(\bullet)$ chest wall volumes are expressed as the difference from the end-expiratory volume at

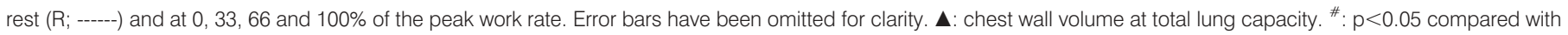
healthy subjects; ${ }^{\bullet}$ p $<0.05$ compared with GOLD stage II patients.

\section{Correlates of exercise tolerance in COPD}

As Wpeak in GOLD stage II patients was limited to the same extent as in GOLD stage III patients, a stepwise multiple regression analysis was performed in order to identify the variables that had an independent significant contribution to the variance of Wpeak. The combination of peak exercise oxygen pulse and leg discomfort explained 35\% of the variance of Wpeak in GOLD stage II and III patients.

\section{Comparison of OEP with spirometric data}

There was a significant difference between ICSP and ICOEP at the limit of tolerance, only in GOLD stage II patients (table 3). The interclass correlation coefficient between the ICSP and ICOEP was 0.92 during exercise in patients and healthy subjects. The mean discrepancy between the two methods was $98 \pm 76 \mathrm{~mL}$ or $4.7 \pm 1.7 \%$.

\section{DISCUSSION}

The main findings of the present study were as follows. 1) Despite individual variability, patients in GOLD stages II-IV exhibited dynamic chest wall hyperinflation at the limit of exercise tolerance, which increased with increasing lung disease severity. Patients in GOLD stages III and IV exhibited substantial increase in $\mathrm{EEV}_{\mathrm{cw}}$ during exercise. These patients did not reduce end-expiratory abdominal volume during exercise, whereas patients in GOLD stage II resembled healthy subjects in that they significantly reduced end-expiratory abdominal volume. 2) In COPD patients of all three stages, the greater the increase in $\mathrm{EEV}_{\mathrm{cw}}$ at the limit of tolerance, the smaller the reduction in end-expiratory abdominal volume and the greater the increase in end-expiratory ribcage volume. 3) Although GOLD stage II patients attenuated dynamic chest wall hyperinflation compared with GOLD stage III patients, peak exercise workload was limited to the same extent as in GOLD stage III. 4) At the limit of exercise tolerance, both GOLD stages III and IV were severely hyperinflated but $V^{\prime} \mathrm{E}$ and exercise workload in GOLD stage IV patients was significantly less than in GOLD stage III patients.

The novel approach of the present investigation is the partitioning of volume regulation between the ribcage and the abdominal compartments of the chest wall during exercise in COPD patients with different lung disease severity, as classified by spirometry. Accordingly, it is suggested that in the early stages of the disease (GOLD stage II), where resting pulmonary hyperinflation (table 1) and the incidence of expiratory flow limitation both at rest and exercise are lower compared with GOLD stages III and IV, expiratory muscle recruitment forces the end-expiratory abdominal volume to decrease during exercise, thereby compensating for the small 

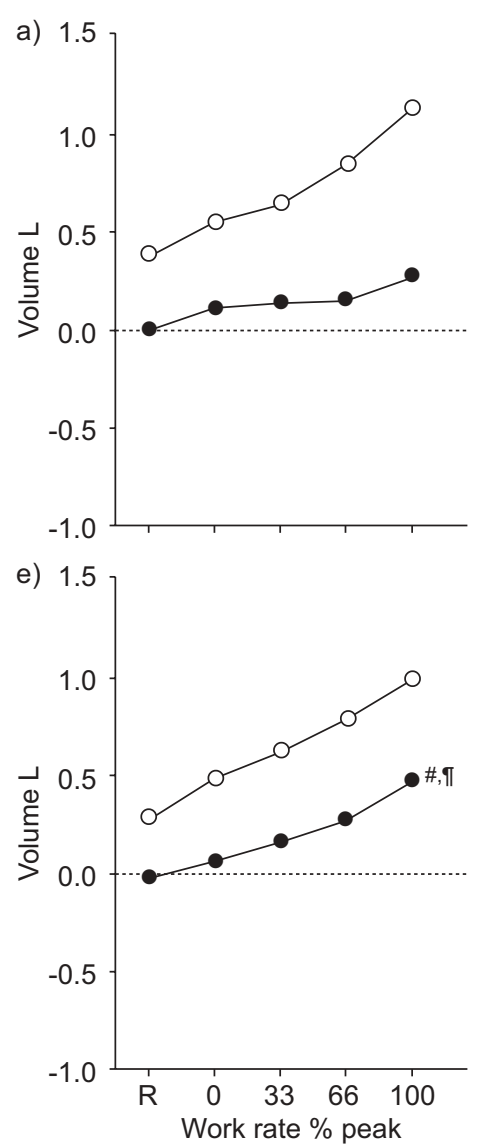
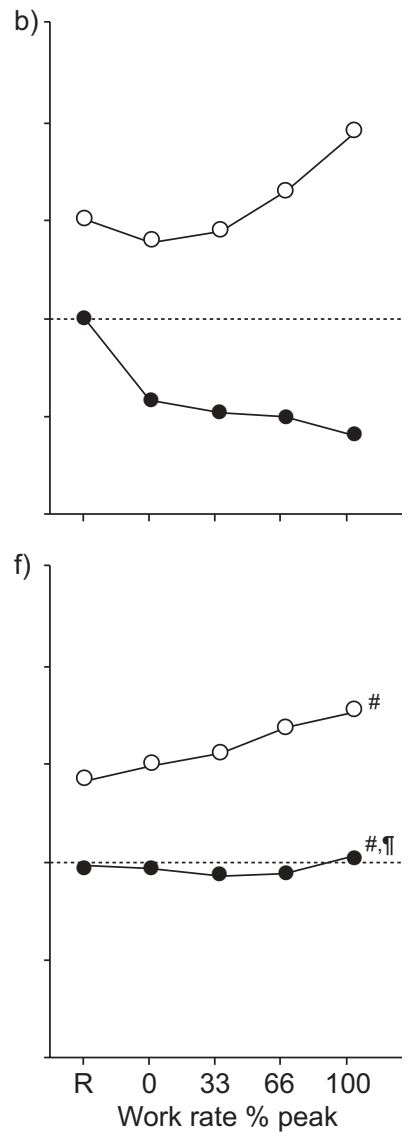

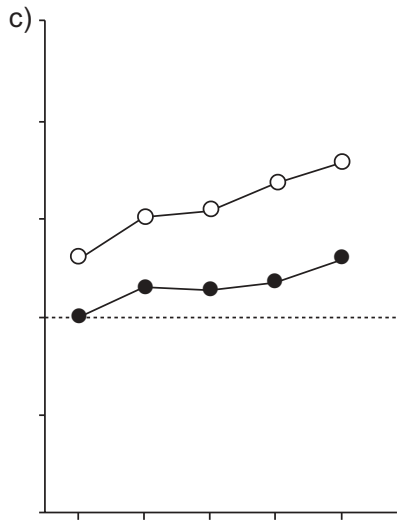

g)

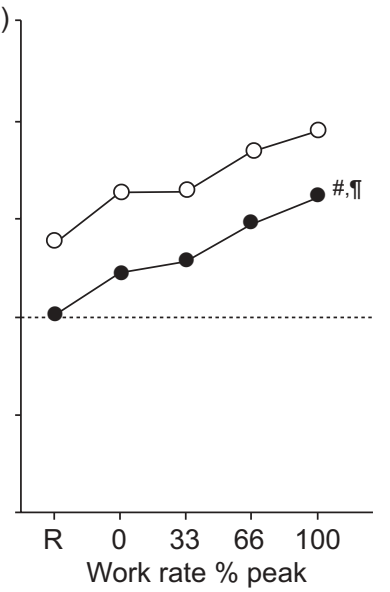

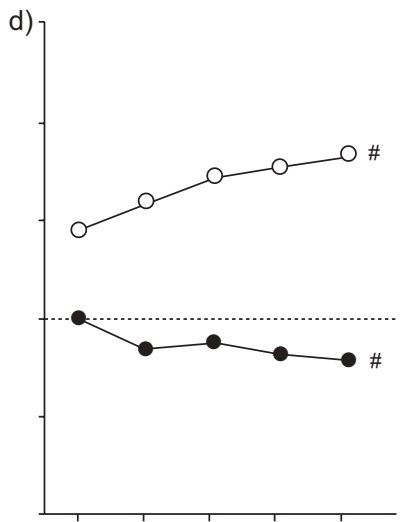

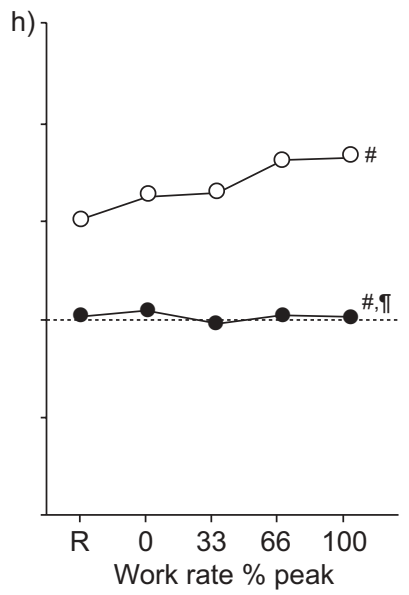

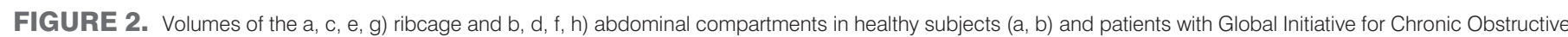

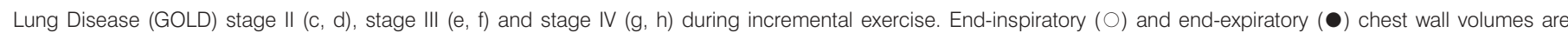

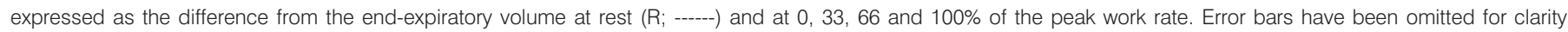
\#: $p<0.05$ compared with healthy subjects; ${ }^{\bullet}: p<0.05$ compared with GOLD stage II patients.

increase in end-expiratory ribcage volume (fig. $2 b$ ). In fact, this is the way normal subjects breathe during exercise [20, 21]. In most cases, this strategy attenuates the progressive increase in $\mathrm{EEV}_{\mathrm{cw}}$ and the occurrence of dynamic chest wall hyperinflation during exercise. Detailed analysis of chest wall volumes and breathing pattern parameters at iso-ventilation during exercise (figs 3 and 4) confirmed that GOLD stage II patients managed to attenuate the substantial chest wall hyperinflation. The most likely explanation is that, since most of the stage II patients did not exhibit expiratory flow limitation during exercise (eight out of 14 patients), expiratory abdominal muscle activity resulted in higher expiratory flow rates compared with GOLD stage III (fig. 4d) and IV (table 3) patients, thereby attenuating the substantial chest wall hyperinflation. Reduced chest wall hyperinflation in GOLD stage II yielded significantly greater duty cycle (fig. 4) compared with stage III.

With disease progression (GOLD stages III and IV) and the presence of expiratory flow limitation at rest and during exercise, expiratory muscle activation was ineffective in terms of reducing end-expiratory abdominal volume, thereby allowing $\mathrm{EEV}_{\mathrm{CW}}$ to rise consequently to the progressive increase in end-expiratory ribcage volume (figs $2 \mathrm{c}, 2 \mathrm{~d}, 3 \mathrm{c}$ and $3 \mathrm{e}$ ).
Measurement of end-expiratory $P$ ga in a fraction of patients (fig. 5) revealed a smaller increase in Pga in GOLD stage III and IV compared with stage II patients. Hence, EEVcw during exercise is modified differently in COPD patients with increasing lung disease severity as classified by spirometry, most likely depending on the degree of expiratory flow limitation and the regulation of both end-expiratory ribcage and abdominal volumes. This argument is in accord with the suggestion that in patients with severe COPD, abdominal muscle recruitment is unlikely to have a significant impact on expiratory flow and end-expiratory lung volume and as such, in energetic terms, it would be advantageous not to use abdominal muscles [22, 23].

The original hypothesis was that in patients with different spirometric severity of COPD, greater degrees of exerciseinduced dynamic chest wall hyperinflation would be accompanied by lesser reductions in end-expiratory abdominal volume. The present results confirm this hypothesis but also highlight the importance of the ribcage compartmental volume regulation as a contributing factor to dynamic chest wall hyperinflation. The observed progressive increase in endexpiratory ribcage volume during exercise, significantly greater in GOLD stages III and IV, might predominantly be 

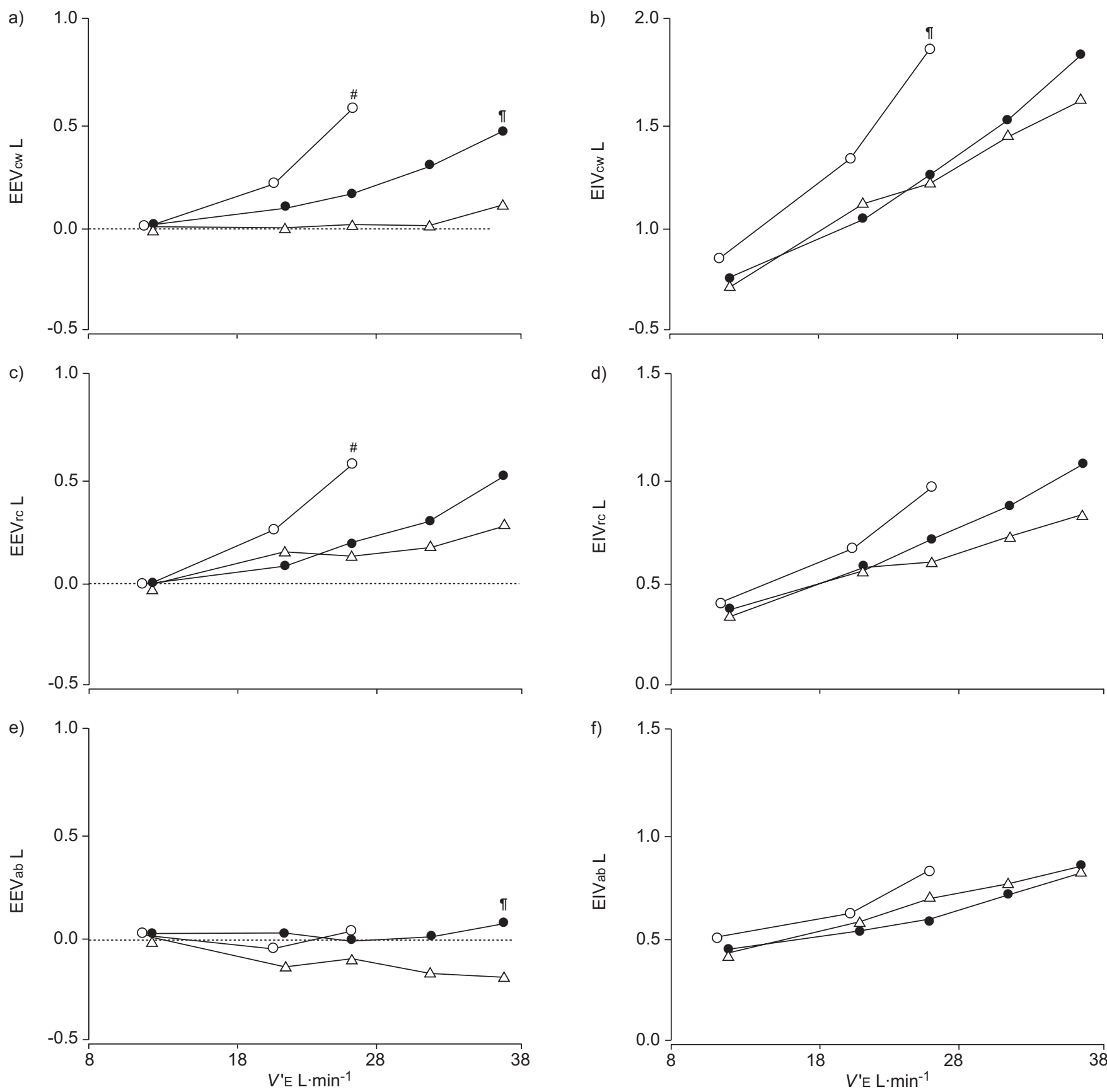

FIGURE 3. Volumes at $a, c$ and e) end-expiration (EEV) and b, $d$ and f) end-inspiration (EIV) of the total chest wall (cw; a, b), the ribcage compartment (rc; $c$, d) and the abdomen (ab; e, f) plotted as a function of minute ventilation $\left(V^{\prime} E\right)$ in patients with Global Initiative for Chronic Obstructive Lung Disease (GOLD) stage II ( $\triangle$ ), stage III $(\bullet)$ and stage IV (O). Error bars have been omitted for clarity. ${ }^{\#}: p<0.05$ compared with GOLD stages II and III; ": $p<0.05$ compared with GOLD stage II patients.

the result of more severe expiratory flow limitation. Additionally, persistent post-inspiratory activity of inspiratory/accessory ribcage muscles, similar to that previously reported during acute bronchoconstriction in asthmatics, might contribute [24].

An additional novelty of the present study is the report of chest wall volume regulation in healthy age-matched subjects and the comparison of the breathing pattern between patients and healthy elderly individuals. Such a comparison revealed that patients with GOLD stage II adopt a similar breathing pattern to that of healthy patients as they both reduce end-expiratory abdominal volume during exercise, whilst exhibiting an increase in $E E V_{c w}$. Such an increase in $E V_{c w}$ is not observed in young healthy individuals [20]. Ageing is known to be associated with decreases in elastic recoil of the lung, chest wall compliance and respiratory muscle performance [25]. Collectively these factors may account for the small endexpiratory ribcage hyperinflation seen in the healthy elderly in the present study. Conversely, there was a striking difference 

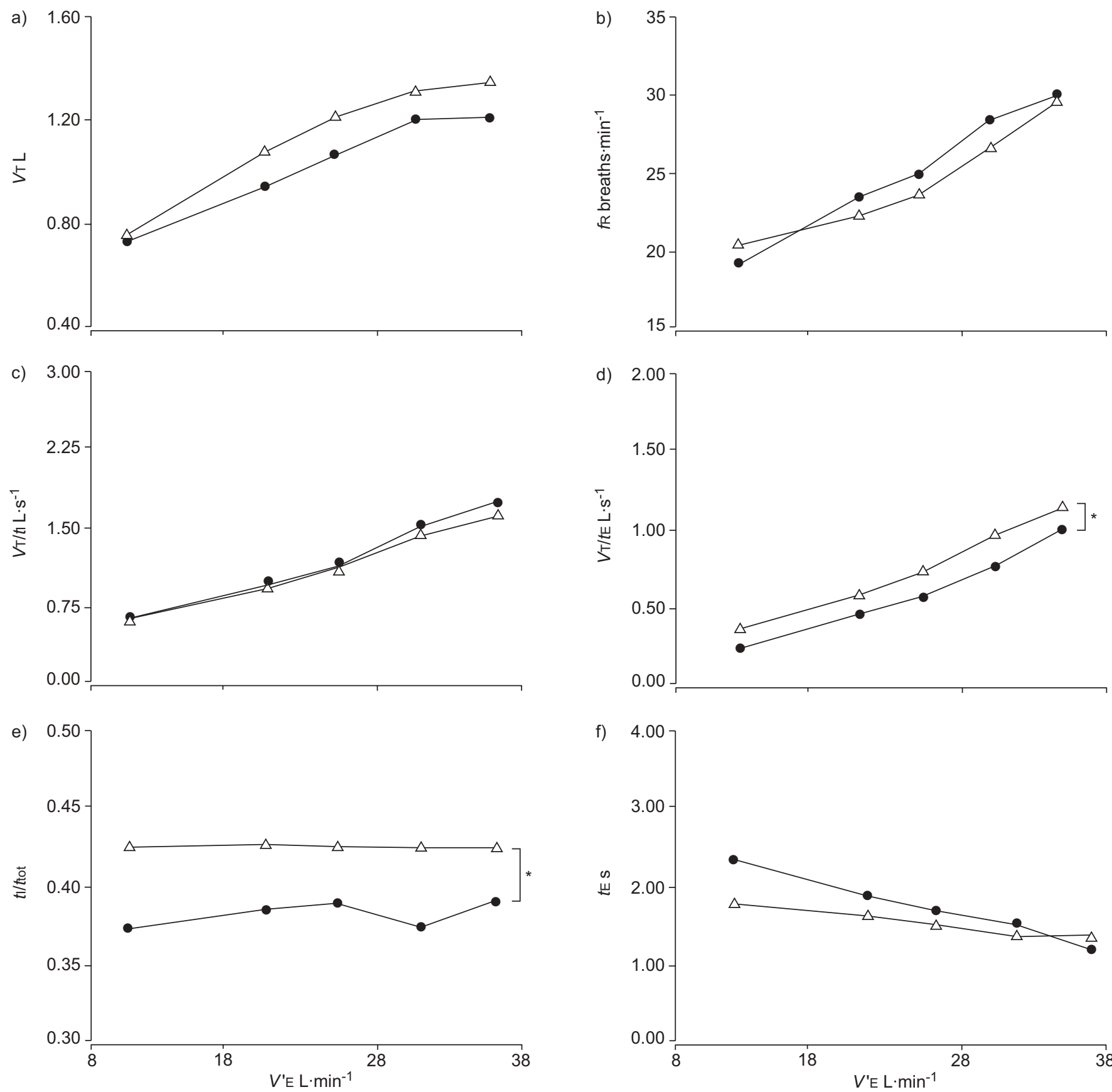

FIGURE 4. Breathing pattern variables: a) tidal volume (VT); b) respiratory frequency (fR); c) mean inspiratory flow rate (VT/tt); d) mean expiratory flow rate (VT/tE); e) duty cycle ( $t / /$ tot); and f) expiratory time ( $t E)$ plotted as a function of minute ventilation $\left(V^{\prime} E\right)$ in patients with Global Initiative for Chronic Obstructive Lung Disease stage II ( $\triangle$ ) and stage III (•). Error bars have been omitted for clarity. *: $p<0.05$.

in the abdominal compartment, in which healthy subjects exhibited significantly greater increases in end-inspiratory volumes compared with COPD patients. The reason for this could potentially be related to beneficial lengthening of the diaphragm during active expiration [20]. Indeed, the greater reduction in end-expiratory abdominal volume in the healthy subjects compared with COPD patients during exercise (fig. 2b, d, f and h) could be associated with increased diaphragm length, greater diaphragmatic power output and descent, and greater expansion of abdominal wall during inspiration [21], resulting in a higher end-inspiratory abdominal volume in healthy subjects than in COPD patients. Nevertheless, at the limit of tolerance, the IRV $\mathrm{cw}$ in stage II patients $(530 \mathrm{~mL})$, and in healthy subjects $(570 \mathrm{~mL})$ remained higher than the "minimum" inspiratory reserve volume (350 mL), which is commonly taken to represent the inability to further expand $V \mathrm{~T}[2,5,7]$. As such, the main reason for terminating exercise in both groups was leg discomfort. 


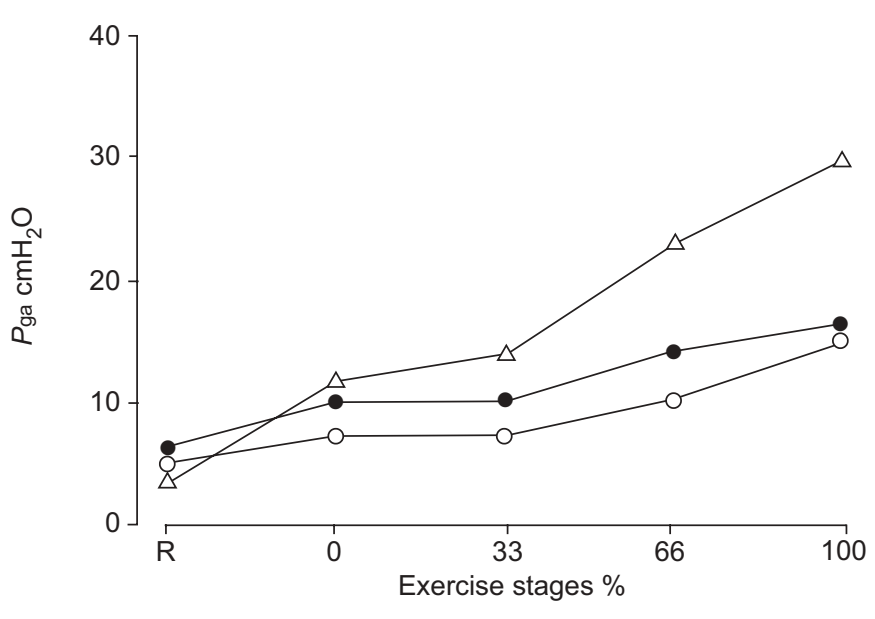

FIGURE 5. End-expiratory gastric pressure $(P$ ga) at rest $(R)$, during unloaded cycling $(0 \%)$ and during incremental exercise (at 33,66 and $100 \%$ of the peak work rate) in patients with chronic obstructive pulmonary disease stratified by Global Initiative for Chronic Obstructive Lung Disease (GOLD) stage II ( $\triangle$ ), stage III (•) and stage IV $(\bigcirc)$. Error bars have been omitted for clarity.

With further disease progression, manifested by further reduction in FEV1 (GOLD stage III) and evidently more severe expiratory flow limitation, both at rest and during exercise, end-expiratory abdominal volume displacement was minimal during exercise. (figs $2 \mathrm{c}$ and $3 \mathrm{e}$ ). Consequently, patients exhibited significant end-expiratory dynamic chest wall hyperinflation, leading to a significant restriction on $V \mathrm{~T}$ expansion that was indicated by the minimal inspiratory reserve volume $(221 \mathrm{~mL})$ at the limit of tolerance $[2,5,7]$. Interestingly, exercise performance was comparable between GOLD stages II and III (table 2). Thus, the strategy of not reducing end-expiratory abdominal volume during exercise seemed to be effective in GOLD stage III patients. This finding is in line with that of ALIVERTI et al. [4] who showed that following bronchodilation, patients who had better exercise performance were those who did not reduce end-expiratory abdominal volume, thus allowing $\mathrm{EEV}_{\mathrm{cw}}$ to rise. In the small number of patients in which it was measured, end-expiratory $P$ ga was greater in patients with GOLD stage II compared with GOLD stage III (fig. 5). Greater activation of abdominal muscles allowed GOLD stage II patients to dynamically hyperinflate much less than GOLD stages III and IV and probably led those patients to stop exercise from leg discomfort rather than dyspnoea (table 2). High expiratory pressures during exercise in patients with COPD [10, 11, 26] and healthy subjects [27, 28] can cause adverse circulatory events that ultimately may impair exercise performance. Under this condition, high expiratory pressures during exercise in patients with GOLD stage II might have caused adverse circulatory effects that ultimately impaired exercise performance resulting in similar peak exercise tolerance in GOLD stages II and III (table 2). In the present study, the combination of peak exercise oxygen pulse and leg discomfort explained $35 \%$ of the variance of exercise tolerance (Wpeak) in patients with GOLD stages II and III. Patients in GOLD stage II had leg discomfort more frequently and tended to have lower oxygen pulse (expressing the volume of oxygen extracted by the peripheral tissues with each beat; an index of stroke volume) compared with stage III patients. Inadequate oxygen supply to meet the metabolic demands of the limb muscles has been alleged to play a more dominant role in limiting exercise capacity in some patients with COPD than impaired lung function or dynamic hyperinflation [29-31].

Although at the severe end of the disease spectrum (GOLD stage IV) there was only a minimal nonsignificant worsening of dynamic chest wall hyperinflation compared with GOLD stage III, exercise tolerance was significantly more impaired compared with that of patients in GOLD stage III. By plotting changes in end-expiratory and end-inspiratory total and compartmental chest wall volumes as a function of $V^{\prime} \mathrm{E}$ (fig. 3), it became evident that for a given level of $V^{\prime} E$ during the incremental exercise test, $\mathrm{EEV}_{\mathrm{cw}}$ in GOLD stage IV patients was greater than those in GOLD stage III. At the limit of tolerance, although both GOLD stages were severely hyperinflated, $V^{\prime} \mathrm{E}$ in GOLD stage IV patients was significantly less than in GOLD stage III, thus explaining why exercise tolerance in GOLD stage IV patients was significantly more impaired than those in GOLD stage III. In other words, both GOLD stages III and IV were severely hyperinflated at the limit of exercise tolerance, and ventilatory limitation should be the main cause to cease exercise (also suggested by the fact that dyspnoea was the most frequent symptom limiting exercise), but this hyperinflation occurred in much lower $V^{\prime} \mathrm{E}$ in GOLD stage IV patients thus resulting in significantly more impaired exercise tolerance in GOLD stage IV than in GOLD stage III patients.

The mean discrepancy $(98 \pm 76 \mathrm{~mL} ; 4.7 \pm 1.7 \%)$ found in the present study between the ICSP and ICOEP during exercise in all subjects is similar to that previously reported in COPD [1]. With the exception of the IC measurements made at the limit of tolerance in GOLD stage II patients, the assessment of IC by the OEP method was in good agreement with that performed by the spirometer (table 3). The discrepancy between the two methods of IC measurement found in GOLD stage II may be explained as follows. GOLD stage II patients used and activated their abdominal muscles (fig. 5) strongly and more than GOLD stages III and IV, thus possibly producing substantial greater gas compression and blood shifts from trunk to limbs during expiration than stages III and IV [26]. During the subsequent IC manoeuvre, the increase in chest wall volume (measured by OEP) was closely approximated not only by the volume of gas inspired (as was the case with spirometry) but also by gas decompression and blood shifting [26]. This justifies the finding that IC measured by OEP was $150 \mathrm{~mL}$ greater compared with spirometry at the limit of tolerance in GOLD stage II patients. Presumably, expiratory muscle activity in GOLD stages III and IV was not high enough to yield a significant difference between the two methods of IC measurement (table 3). Although the magnitude of change in spirometric IC from rest to the limit of tolerance in stage II patients $(280 \mathrm{~mL})$ was within the range previously reported by O'DONNELL et al. [32] in such patients, the discrepancy between the two methods (OEP and spirometry) in IC measurements in GOLD stage II patients emphasises the difference between dynamic pulmonary and chest wall hyperinflation; the former reflects exclusively air trapping, whereas the latter manifests air trapping, blood shifting and gas compression. Nevertheless, OEP can provide important complementary information 
to the spirometric IC method as it allows concomitant assessment of volume variations of the ribcage and abdominal compartments during exercise in patients with COPD.

In conclusion, the present study shows that in chronic obstructive pulmonary disease patients with different spirometric disease severity, greater degrees of airway obstruction, expiratory flow limitation and exercise-induced dynamic chest wall hyperinflation are accompanied by lower degrees of end-expiratory abdominal volume displacement and larger increases in end-expiratory ribcage volume.

\section{REFERENCES}

1 Vogiatzis I, Georgiadou O, Golemati S, et al. Patterns of dynamic hyperinflation during exercise and recovery in patients with severe chronic obstructive pulmonary disease. Thorax 2005; 60: 723-729.

2 O’Donnell DE, Revill SM, Webb KA. Dynamic hyperinflation and exercise intolerance in chronic obstructive pulmonary disease. Am J Respir Crit Care Med 2001; 164: 770-777.

3 Babb TG, Viggiano R, Hurley B, Staats B, Rodarte JR. Effect of mild-to-moderate airflow limitation on exercise capacity. J Appl Physiol 1991; 70: 223-230.

4 Aliverti A, Rodger K, Dellacà RL, et al. Effect of salbutamol on lung function and chest wall volumes at rest and during exercise in COPD. Thorax 2005; 60: 916-924.

5 O'Donnell DE, Flüge T, Gerken F, et al. Effects of tiotropium on lung hyperinflation, dyspnoea and exercise tolerance in COPD. Eur Respir J 2004; 23: 832-840.

6 Somfay A, Pórszász J, Lee SM, Casaburi R. Dose-response effect of oxygen on hyperinflation and exercise endurance in nonhypoxaemic COPD patients. Eur Respir J 2001; 18: 77-84.

7 O'Donnell DE, D'Arsigny C, Webb KA. Effects of hyperoxia on ventilatory limitation during exercise in advanced chronic obstructive pulmonary disease. Am J Respir Crit Care Med 2001; 163: 892-898.

8 Puente-Maestu L, Abad YM, Pedraza F, Sánchez G, Stringer WW. A controlled trial of the effects of leg training on breathing pattern and dynamic hyperinflation in severe COPD. Lung 2006; 184: 159-167.

9 Georgiadou O, Vogiatzis I, Stratakos G, et al. Effects of pulmonary rehabilitation on operational chest wall volumes during exercise in COPD patients. Eur Respir J 2007; 29: 284-291.

10 Aliverti A, Stevenson N, Dellacà RL, Lo Mauro A, Pedotti A, Calverley PM. Regional chest wall volumes during exercise in chronic obstructive pulmonary disease. Thorax 2004; 59: 210-216.

11 Potter WA, Olafsson S, Hyatt RE. Ventilatory mechanics and expiratory flow limitation during exercise in patients with obstructive lung disease. J Clin Invest 1971; 50: 910-919.

12 Leaver DG, Pride NB. Flow-volume curves and expiratory pressures during exercise in patients with chronic airways obstruction. Scand J Respir Dis Suppl 1971; 77: 23-27.

13 Global Initiative for Chronic Obstructive Lung Disease. Global strategy for the diagnosis, management, and prevention of chronic obstructive pulmonary disease. Executive summary, 2005. www.goldcopd.com/guidelineitem.asp?11 $=2 \& 12=1 \& \operatorname{int} \mathrm{Id}=1816$ Date last updated: 2007 .
14 Wanger J, Clausen JL, Coates A, et al. Standardisation of the measurement of lung volumes". Eur Respir J 2005; 26: 511-522.

15 Borg GA. Psychophysical bases of perceived exertion. Med Sci Sports Exerc 1982; 14: 377-381.

16 American Thoracic Society, American College of Chest Physicians. ATS/ACCP Statement on cardiopulmonary exercise testing. Am J Respir Crit Care Med 2003; 167: 211-277.

17 Palange $\mathrm{P}$, Ward SA, Carlsen K-H, et al. Recommendations on the use of exercise testing in clinical practice. Eur Respir J 2007; 29: 185-209.

18 Johnson BD, Reddan WG, Pegelow DF, Seow KC, Dempsey JA. Flow limitation and regulation of functional residual capacity during exercise in a physically active aging population. Am Rev Respir Dis 1991; 143: 960-967.

19 Vogiatzis I, Aliverti A, Golemati S, et al. Respiratory kinematics by optoelectronic plethysmography during exercise in men and women. Eur J Appl Physiol 2005; 93: 581-587.

20 Aliverti A, Cala SJ, Duranti R, et al. Human respiratory muscle actions and control during exercise. J Appl Physiol 1997; 83: 1256-1269.

21 Aliverti A, Iandelli I, Duranti R, et al. Respiratory muscle dynamics and control during exercise with externally imposed expiratory flow limitation. J Appl Physiol 2002; 92: 1953-1963.

22 Ninane V, Rypens F, Yernault JC, De Troyer A. Abdominal muscle use during breathing in patients with chronic airflow obstruction. Am J Respir Dis 1992; 146: 16-21.

23 Polkey MI, Kyroussis D, Hamnegard CH, et al. Diaphragm performance during maximal voluntary ventilation in chronic obstructive pulmonary disease. Am J Respir Crit Care Med 1997; 155: 642-648.

24 Gorini M, Iandelli I, Misuri G, et al. Chest wall hyperinflation during acute bronchoconstriction in asthma. Am J Respir Crit Care Med 1999; 160: 808-816.

25 Frank NR, Mead J, Ferris BG Jr. The mechanical behaviour of the lungs in healthy elderly persons. J Clin Invest 1957; 36: 1680-1687.

26 Macklem PT. Exercise in COPD: damned if you do and damned if you don't. Thorax 2005; 60: 887-888.

27 Aliverti A, Dellacà RL, Lotti $\mathrm{P}$, et al. Influence of expiratory flow-limitation during exercise on systemic oxygen delivery in humans. Eur J Appl Physiol 2005; 95: 229-242.

28 Vogiatzis I, Zakynthinos S, Georgiadou O, et al. Oxygen kinetics and debt during recovery from expiratory flowlimited exercise in healthy humans. Eur J Appl Physiol 2007; 99: 265-274.

29 Simon M, Le Blanc P, Jobin J, Desmeules M, Sullivan MJ, Maltais F. Limitation of lower limb $\mathrm{VO}(2)$ during cycling exercise in COPD patients. J Appl Physiol 2001; 90: 1013-1019.

30 Montes de Oca M, Rassulo J, Celli BR. Respiratory muscle and cardiopulmonary function during exercise in very severe COPD. Am J Respir Crit Care Med 1996; 154: 1284-1289.

31 Aliverti A, Macklem PT. How and why exercise is impaired in COPD. Respiration 2001; 68: 229-239.

32 O'Donnell DE, Kesten S, Magnussen H, Leimer I, Hamilton A. Effects of tiotropium on lung volumes during exercise in GOLD stages II to IV COPD patients. Eur Respir J 2006; 28: Suppl. 50, 171s. 